\title{
Our Way Towards the Integration of Digital Technology
}

\author{
Dr. Nikollaq Pano \\ Mediterranean University of Albania, \\ Tirana, Albania \\ Dr. Ira Gjika \\ Mediterranean University of Albania, \\ Tirana, Albania
}

\begin{abstract}
Information and communication technologies (ICT) are stirring the worldwide economic advancement for more than three decades. The new technologies and their implementation in manufacturing, services, as well as the public sector, have provided changes of the economic structure and - hopefully - increase of productivity. The factors driving the use of ICT come from the demand side, for products and services the companies and consumers require, as well as from the supply side, with solutions and models applicable to a rising number of users. The extent of using the information and communication technologies in Albanian environment is in the focus of this paper. The main objective is, firstly to highlight the assessment of digital technology integration in Albanian economy, particularly in businesses. Another objective is to analyze major reasons that brought changes during the last years. Further on, the chances for Albanian businesses to take advantage of the economic and social benefits from ICT should be considered. The research work has combined the "desk study" with on-site survey in order to evidence the achievements, shortcomings and opportunities for a higher level of integration of digital technology in Albanian organizations.
\end{abstract}

Keywords: business digitization, integration of digital technology, e-commerce, internet use, SME-s

\section{Introduction}

Information and communication technologies (ICT) have been since the 1990-s at the center of economic changes and getting the most of attention from the international organizations like UN, OECD, EU and others. ICT has become a core technology driving Science Technology and Innovation in economies worldwide. Such awareness is closely related to the important role the ICT sector has played and is expected to bring onward in coming years.

For a consistent approach during the realization of this study, we have been based on OECD definition of ICT-producing industries, as stated in 2002:

"The principles are the following: for manufacturing industries, the products of an industry must be intended to fulfil the function of information processing and 


\section{Journal of International Cooperation and Development \\ www.richtmann.org/journal \\ Vol 3, No 1, May 2020}

communication including transmission and display, or must use electronic processing to detect, measure and/or record physical phenomena or control a physical process.

For services industries, the products must be intended to enable the function of information processing and communication by electronic means." (OECD, 2002).

In simpler wording, it encompasses all devices, components, applications and systems that allow people and organizations to network and interact in the digital world, such as mobile networks, Internet, satellite communications, as well as the more traditional landline communications, radio and television broadcast.

In general terms, the sector has the potential to provide high quality communication for everyone, despite differences in age, gender, location, language spoken or other physical features. According to a recent study from International Telecommunication Union, it is highly expected to contribute to economic growth and facilitate business operations, although the speed of change can vary between countries and time periods. ICT is changing both the process of knowledge creation as well as its diffusion, and it is affecting the global competitiveness (ITU, 2016).

\subsection{Objectives and research method}

The scope of this study involves the use of digital technologies in the Albanian environment, mainly in the business sector. The main objectives are:

- reviewing and highlighting the involvement of ICT in Albanian companies, then

- assessment of changes that have occurred in the country over the years in this sector, using standard indicators and finally

- discussion of some development trends that could affect the future expansion of the market.

The research method is a combination of desk and field study. The paper initially presents an introduction to the features and development of ICT based on the literature review, which is mainly of a research nature at the international organizations level.

The role of the definition and measurement of DT integration indicators is then evidenced, as a driving force for the further development of this integration. This part too is carried out by desk-study, in the form of a comparative observation.

In the end, recent questionnaire results from INSTAT and our surveys in Albanian companies are presented. Results are derived on the basis of standard questionnaires and processed according to Eurostat's methodology, for comparability purposes (INSTAT, 2018). The empirical analysis of results aims to highlight trends and opportunities for DT integration in organizations level, as well as in country level.

Despite the tremendous role of ICT in the lives of every individual, the paper is focused on the company / organization level, which is one of its limitations.

Another limitation of this work is the relatively small number of companies visited and interviewed in order to identify obstacles and opportunities for wider ICT involvement in businesses. 


\section{Journal of International Cooperation and Development \\ www.richtmann.org/journal \\ Vol 3, No 1, May 2020}

\section{Diffusion of Digital Technology in Economy - Theoretical Considerations}

New technologies and their implementation in productive activities and public sector have brought to outstanding changes in the economic structure of countries. As evidenced by analysts from London School of Economics and Political Science, there are three milestones: The launch of 'desktop' personal computing in 1982 introduced a large section of the public to regular ICT usage in both their working and personal lives. This was followed up by at least two further major ICT diffusion events - the emergence of the commercial internet in the mid-1990s and the rise of mobile computing devices in the late 2000s (LSE, 2018).

\subsection{What brings the spread of ICT}

The diffusion of ICT in different countries and regions has been analyzed in order to obtain positive effects from it, as well as to forecast - as much as possible - the role it can play in macro and micro level of economic activities. It is well accepted that ICT innovation in recent decades has created tremendous value in the global economy (OECD, 2002), (LSE, 2018). This innovation has been driven, at least at the moments of presenting new inventions, by the supply of creative and ingenious solutions. We do refer mainly to the above-mentioned milestones that did engage whole manufacturing and service- provider companies into offering more and more products of ICT to the public sector, other industries and individuals worldwide.

From the other side, it has been the consumer and business demand for novel and effective products and services, which has further encouraged the development and innovation in ICT sector, making it a very expansive one for several decades. In a global perspective, researchers point out that the speed of growth is slowing though, with most of the developed world approaching saturation (LSE, 2018), (GSMA, 2018). The recent forecasts do provide optimistic prognosis, mentioning that more significant growth opportunity will lie in mobile internet - a market that will add 1.75 billion new users over the next eight years, reaching a milestone of 5 billion mobile internet users in 2025 (GSMA, 2018), (OECD, 2017). Although the focus of such forecasts is sometimes the future of mobile industry, it still tremendously highlights the impact of this industry in the whole economic activities. As GSMA report articulates it, "mobile internet adoption is indivisible from the developments in the wider digital ecosystem, as mobile internet users are the addressable market for e-commerce, the emerging 'fintech' industry and a range of digitally delivered services and content", (GSMA, 2018).

ICT is granted the role of a generator of ideas. The LSE study concludes that ICT technologies generate on average substantially larger knowledge spillovers than those generated by other technology areas and this holds even when ICT is compared to other frontier fields such as biotech and clean energy (LSE, 2018). New ICT solutions can be 


\section{Journal of International Cooperation and Development \\ www.richtmann.org/journal \\ Vol 3, No 1, May 2020}

generated and/ or applied in the private and public sectors in a country through stimulation of innovation processes. It is generally considered as a major component in facilitating a country's efforts towards creating a thriving and knowledge-based economy.

From the global point of view, as the international organizations deal with it, "this (in turn) ensures that all countries have the opportunity to enjoy the economic and social benefits of ICTs. More specifically, countries will be able to steer ICTs for development solutions, using innovative ICTs to address social and economic problems faced by the world" (ITU, 2016). Our research work modestly intends to view Albania in this emplacement.

The role of ICT in a macro perspective is closely related to the cost of investment in the sector. This one and other factors affecting the diffusion of ICT are considered during the years in detailed analysis (OECD, 2018), but they go beyond the scope of this work. However, it is common knowledge that companies in countries with higher levels of income and productivity typically are more inclined to invest in such technologies than countries at lower levels of income, where Albania is included. This statement became a driver for our following review and investigation.

\subsection{Impacts of ICT at the company level}

While handling the role of ICT from the company's perspective, the focus might be - on the ICT-production side, - on those sectors of the economy that are intensive users of ICT, most of which belong to the services sector, (e.g. industries such as finance, business services and distribution, although the range of activities is growing rapidly), or on both production and consumption/ users side. The choice of last option permits the provision of a broader understanding for the ICT impacts, particularly in the Albanian framework.

From an economic point of view, the decision of a company to adopt ICT depends on the trade-off between costs and benefits that may derive from the technology' use. There are different factors that companies might consider before such decision, including amongst others: high costs of technology itself, lack of know-how or relevant skills for effective use of ICT, insufficient security and slow or unstable communications.

Studies with company-level data often find the strongest evidence for economic impacts of ICT. Porter and Heppelmann suggest that "the role of ICT in helping firms gain market share can be examined in combination with the role of organizational change" (Porter, Heppelmann, 2017). Management experience reveals significant interactions between ICT use and complementary organizational variables in the companies. As Boudreau underlines in his research work "the complementary factors having significant influence are: human capital, a firm's experience in innovation, its use of advanced business practices and the intensity of organizational restructuring" (Boudreau, 2015). 


\section{Journal of International Cooperation and Development \\ www.richtmann.org/journal \\ Vol 3, No 1, May 2020}

There is one more specific issue we want to point out before going into countrylevel discussion of digital technology' integration. We strongly give credit to the statement by Burning Glass Technologies (2015) that effective use of ICTs in life and for work requires adequate skills. "IT staff" ranks second among the top ten jobs that employers have difficulties filling, notably in services. Meanwhile, as evidenced for several countries (OECD, 2017), (UNESCO, 2018), generic ICT skills are insufficient among many workers using ICTs every day, as are ICT foundational skills, such as problem solving and communication, which are increasingly necessary to adapt to changing jobs. These "pros and cons" are necessarily mixed in topics below that are focused in the country situation.

\section{Tracking the ICT Sector in Country}

The integration of information and communication technology has influenced the evolution of the digital market in Albania, a market made up of products and services as defined by the OECD (2002), given at the opening of this paper. The development of this market is mainly noted through the expansion of goods, including the digital infrastructure, and the progress of the market' subjects. The subsequent short preview both in country and in company level precedes main discussion on DT spreading in Albania.

\subsection{The national dimension}

The digital market in Albania has gone through a rapid development of all its elements during the last decade. Its growth rates are higher than the average GDP growth rate of the country, which is a premise for a major role in economic development and an increasing impact on the economic and social life of the country. The development of digital infrastructure in the mid-2000s has made it possible to rapidly change the ability of the population to gain access to digital technology, although ITU Country review Albania emphasizes there is still room for improvement (ITU, 2016).

Technology and innovation did receive greater attention in this period, as endorsed by 2009-2015 National Strategy for Science, Technology and Innovation (STI), as well as subsequently by "Digital Agenda 2015-2020". This last one considers the Information and Communication Technologies (ICT) as a core enabler to Albania's development (Ministry of Innovation and Public Administration, Albania 2014).

Regarding the use of technologies, after year 2007 in Albania consideration was given to the possibility of internet connection, as well as to the ability of the population to utilize the instruments and products available from this digital infrastructure. Consequently, indicators for assessment of Internet connectivity were complemented with indicators of the use of other products offered by ICT, provided by many sectors 


\section{Journal of International Cooperation and Development \\ www.richtmann.org/journal \\ Vol 3, No 1, May 2020}

such as trade, banking, education, public administration, etc. (e-commerce, e-banking, e-learning).

According to the data from AKEP (2018), the geographical coverage of internet access has increased by $67 \%$ for the period 2007-2017. An increase was observed in the use of the Internet by private entities, which was $87 \%$ higher in 2016 compared to 2007. The same trend is noticed regarding the use of public/ national platforms, starting with the tax administration and afterwards followed by a number of other institutions (eAlbania). From 2010, all processing operations between tax administration and large businesses became digitalized, by degrees during a three-year period; the same process was done for the small businesses as well, from 2016 and on (DPT- General Tax Directorate).

\subsection{Growth of digital market subjects}

Another indicator of the fast growth of the digital market is the increase of digital suppliers (companies that produce and / or sell services, infrastructure or goods of the digital market) and entities using digital products / services.

According to the data generated by public institutions, processed and published by interested parties (AITA, 2016), (Telekom Albania, 2017), the situation of ICT sector development in Albania by the end of 2017 is presented by a quantitative and qualitative data preview. There are over 200 IT companies operating within the country, the majority of which are small and medium-sized companies. Albanian ICT companies specialize in software design and development, system integration and hardware distribution. There are over 8000 IT professionals, with 10 universities teaching ITregulated subjects and approximately 1700 IT graduates each year (for the last 3 years, 2015-2017) (INSTAT). The increasing quality of national IT education strongly supports the sector's future growth. Approximately $80 \%$ of ICT companies work with international companies in domestic market, which contributes to the knowledge spillover effect (Telekom Albania, 2017).

The amount of digital technology' integration in the Albanian economy, particularly in business activities, is the subject of the hereinafter discussion.

\section{Considerations about the Measurement of Digital Technology Integration}

Over the past years, much progress has been made in developing statistics on the use of various ICT technologies in the economy (OECD, 2002, 2017), (ITU, 2017). In addition, many countries have developed databases that provide detailed and comprehensive data on the performance of individual firms (EC, 2017), (EC, 2018). The correlation between use of ICT in the companies and their performance indicators might be observed due to the analysis of above mentioned combined information. 


\section{Journal of International Cooperation and Development \\ www.richtmann.org/journal \\ Vol 3, No 1, May 2020}

\subsection{Many facets, different indicators}

The involvement of digital technologies in all sectors of activity and in all countries, especially those developed and developing ones, has fostered the efforts of many organisms to determine indicators and to measure ICT. The ICT Development Index (IDI) is an index published by the United Nations International Telecommunication Union, based on internationally agreed information and communication technologies (ICT) indicators (ITU, 2017). This makes it a valuable tool for benchmarking the most important indicators for measuring the information society. The IDI is a standard tool that governments, operators, development agencies, researchers and others can use to measure the digital divide and compare ICT performance within and across countries. The ICT Development Index is based on 11 ICT indicators, grouped in three clusters: access, use and skills.

This indicator shows an improvement for Albania, raising from a value of 4,9 in 2016 to a value of 5.14 on 2017 (Figure 1). Nevertheless, in both last years the country remains ranked at the 89-th place, in a list of 176 countries evaluated, where the index value varies from 8,98 (for the first place) to 0.96 (for the last ranked country) (ITU, 2017).

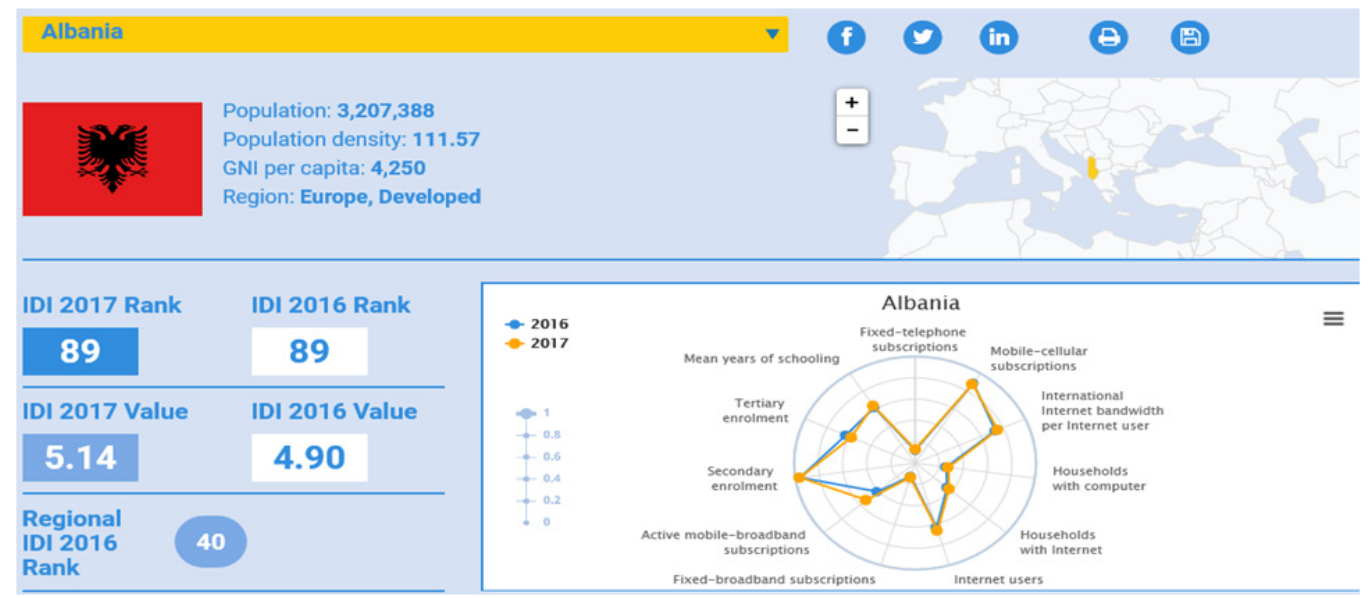

Figure 1: ICT Development Index (IDI) Albania, 2017

Source: ITU

In the continental landscape, the European Commission deals with the integration of DT in the framework of the Digital Single Market (DSM). The Digital Economy and Society Index (DESI) Report aims to help EU countries identify areas requiring priority investments and action in order to create a truly Digital Single Market (EC, 2017).

The Digital Intensity Index (DII) measures the availability at firm level of 12 different 


\section{Journal of International Cooperation and Development \\ www.richtmann.org/journal \\ Vol 3, No 1, May 2020}

digital technologies, trying to make yearly measuring and analysis (Figure 2).

European businesses are increasingly adopting digital technologies, such as the use of a business software for electronic information sharing (from 26\% in 2013 to $34 \%$ of enterprises in 2017), sending electronic invoices (from 10\% in 2013 to 18\% of enterprises in 2016) or using social media to engage with customers and partners (from $15 \%$ in 2013 to $21 \%$ of enterprises in 2017), as reported by EC (DESI report 2017).

\begin{tabular}{|c|c|c|c|c|c|}
\hline \multirow{2}{*}{ Key indicators tracking digitisation processes } & \multirow{2}{*}{ Year } & \multicolumn{2}{|c|}{$\%$ of EU28 enterprises } & \multicolumn{2}{|c|}{ Variation 2017-2015 (pp) } \\
\hline & & Large & SMES & Large & SMES \\
\hline Having a web site or homepage & 2017 & $94 \%$ & $76 \%$ & & 2 \\
\hline Website has some interactive functionalities & 2017 & $74 \%$ & $58 \%$ & 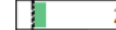 & 3 \\
\hline Use any social media & 2017 & $72 \%$ & $47 \%$ & se & 8 \\
\hline$>50 \%$ of the persons employed use computers \& Internet & 2017 & $50 \%$ & $40 \%$ & 3 & 2 \\
\hline Fastest broadband connection is at least $30 \mathrm{Mb} / \mathrm{s}$ & 2017 & $69 \%$ & $37 \%$ & 1 & 12 \\
\hline Have ERP software package to share information & 2017 & $76 \%$ & $33 \%$ & Not comparabl & th 2015 \\
\hline Use Customer Relationship Management (CRM) & 2017 & $62 \%$ & $32 \%$ & & 1 \\
\hline$>20 \%$ of workers with portable devices for business use & 2017 & $38 \%$ & $32 \%$ & i & 5 \\
\hline Employ ICT specialist & & $75 \%$ & $18 \%$ & -1 & -1 \\
\hline Selling online (at least $1 \%$ of turnover) & 2017 & $39 \%$ & $17 \%$ & 7 & 1 \\
\hline Share electronically supply chain management data & 2017 & $47 \%$ & $17 \%$ & - & \\
\hline Exploit B2C eCommerce & 2017 & $9 \%$ & $7 \%$ & & 1 \\
\hline
\end{tabular}

Figure 2: Key indicators tracking digitization processes.

Source: European Commission services based on Eurostat data

Given the above illustrated course, the EU standardized methodology enables evaluation of different features and aspects related to ICT use. The current approach for assessing the Integration of Digital Technology takes in consideration two dimensions (a) 'business digitization' and (b) 'e-commerce'.

'Business digitization' has five indicators (as \% of firms using): electronic information sharing, Radio Frequency Identification (RFID), social media, e Invoices and cloud solutions.

E-commerce has three indicators: the percentage of small and medium-sized enterprises (SMEs) selling online, e-commerce turnover as a percentage of total turnover of SMEs; and the percentage of SMEs selling online cross-border.

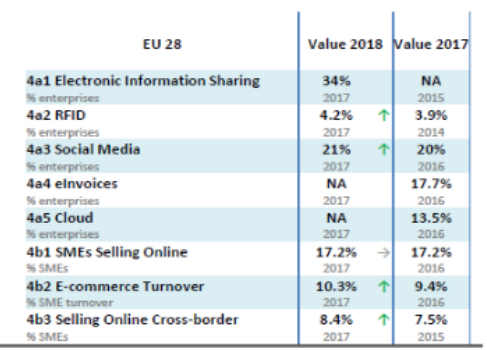

\begin{tabular}{l|ccc|ccc}
\hline E-sales and turnover from e-sales, by firm size, EU, 2010 - 2017 \\
(\% of enterprises, \% of turnover)
\end{tabular}

Figure 3: Measuring the integration of DT in EU countries

Source: European Commission services based on Eurostat data 


\section{Journal of International Cooperation and Development \\ www.richtmann.org/journal \\ Vol 3, No 1, May 2020}

\subsection{ICT indices in Albanian business environment}

The European methodology for analyzing data related to integration of digital technology has been lately adopted by the Albanian public Institution of Statistics (INSTAT). The first official report was released in 2015, based on the survey of year 2014 in the company' level. As a first step, it provided partial indicators regarding the phenomenon. However, the survey was repeated yearly since then, enabling broader overview and analysis, at least in 2018 (INSTAT, 2018). As officially announced by INSTAT, the survey was based on the Eurostat methodology, consequently providing us with data and results comparable to those displayed for EU countries (referred in fig.2 and fig.3). The sample was made of 1558 companies of different sizes and economic activities, acc. NACE Rev.2 (INSTAT, 2018).

Our analysis is built both on the data collected by above survey and on their further processing, to bring most important and significative indices related to the level of DT integration in Albanian companies. The interviews in the companies with top managers have permitted to deepen the analysis and draw some conclusions.

There are measured four indicators, amongst the key indicators fixed to track the digitization processes (ref. figure 2), providing the following view according to the economic activities in 2017 (fig. 4).

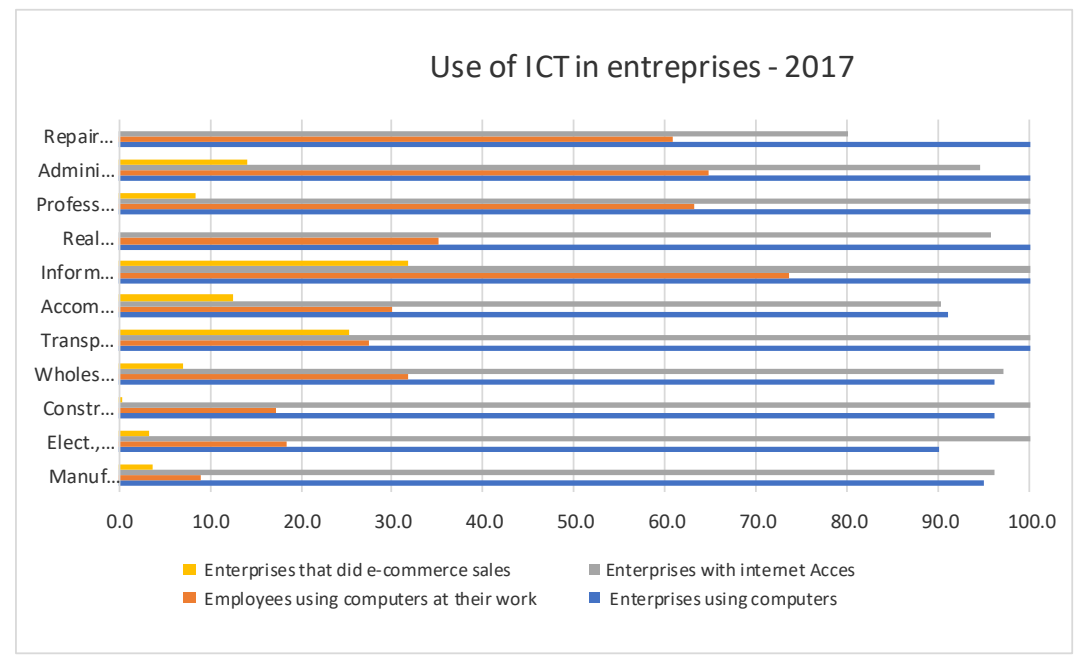

Figure 4. Use of ICT in companies according economic activity, year 2017 Source: INSTAT, processed by authors

Enterprises that used the computer for work purposes, during 2017, represent $96.0 \%$ of economic enterprises, from $95.6 \%$ in 2016 . The increasing trend is more valuable than 


\section{Journal of International Cooperation and Development \\ www.richtmann.org/journal \\ Vol 3, No 1, May 2020}

the amount itself in a yearly period. Moreover, the figure is quite close to the maximum $(100 \%)$. The percentage of enterprises with internet access is $96.9 \%$ of total enterprises, while in the EU member states this indicator is $97.0 \%$.

During 2017, the percentage of enterprises that have employed an ICT Specialist is $22.4 \%$, from $21.9 \%$ in 2016. Again, it is the trend counting more than the amount, as it encourages advances in the other indices of digital technology integration. This outcome has been derived from the interviews in the companies, when asked about the role of ICT specialists, their skills and competencies. However, the lack of qualified ICT graduates, higher cost of these professionals (although missing qualification) and the long period of payback for ICT investments are the main factors refraining surveyed Albanian companies from a broader integration of digital technologies.

Findings from EU survey (DESI 2017) are applicable in a great extent in our country situation as well. The adoption of digital technologies varies strongly with company size. Large enterprises have a scale advantage and more capacity to employ at least some IT/ICT specialists.

However, small and medium sized companies offer a good experience regarding employees using computers at their work and in e-sales respectively.
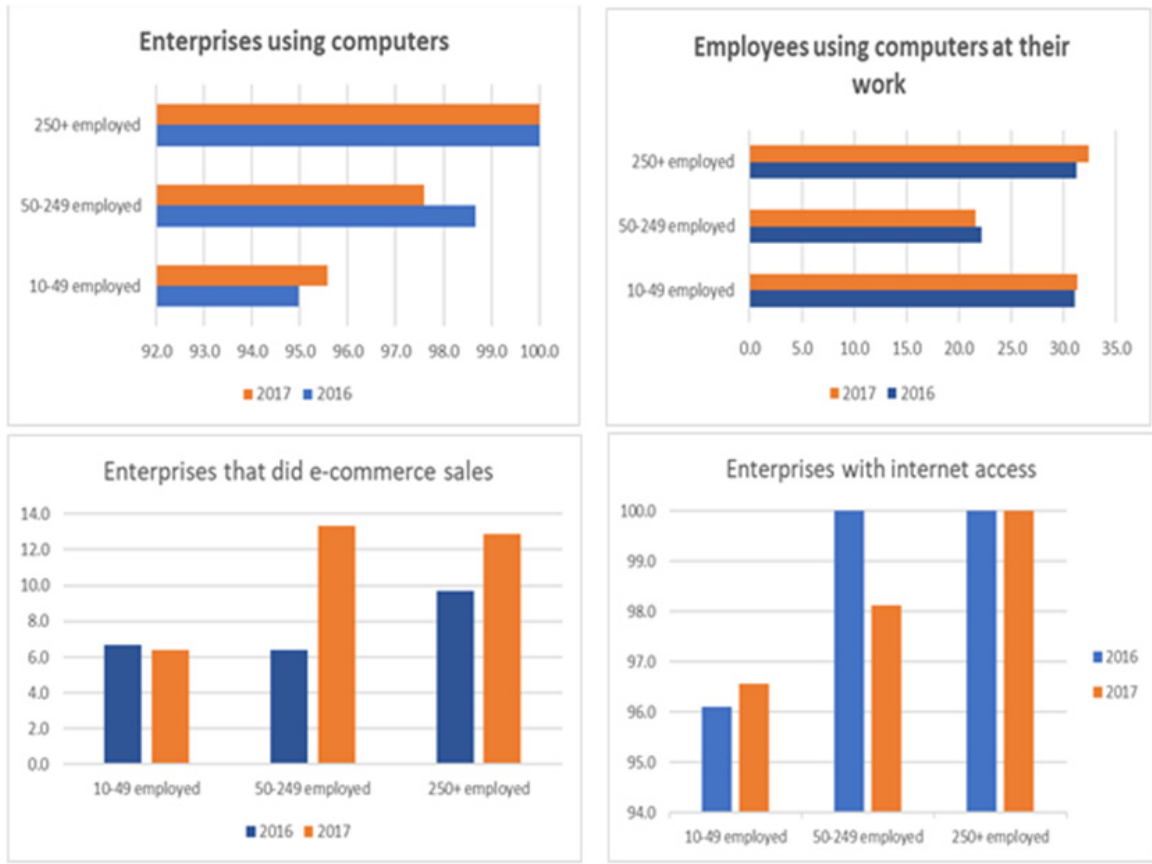

Figure 5. Some key indicators of DT integration according to company size in two last years Source: INSTAT, processed by authors 


\section{Journal of International Cooperation and Development \\ www.richtmann.org/journal \\ Vol 3, No 1, May 2020}

The INSTAT survey for 2017 reveals that share of employees using the computer for work purposes account for $28.1 \%$ of the total enterprise employees, from $28.0 \%$ in 2016. The lowest share of employees using the computer is in the manufacturing activities with $8.9 \%$ and construction activity with $17.2 \%$. As can be expected and as the EU countries' experience shows, computers are used to a greater extent by employees of enterprises that perform in information and communication sector by $73.6 \%$, administrative and support services by $64.7 \%$ and employees in professional, scientific and technical activities by $63.3 \%$. They are the most digitized sectors of the economy, however the average indicator for all the economic activities is only $28.1 \%$. The sectors following the first group and tend to become more digitized are real estate activities, wholesale trade and accommodation. This is in tune with findings from EU survey, that points out "other sectors such as accommodation, travel agencies, cultural industries (publishing, film \& television) and the wholesale trade are also highly digitized (DESI 2017). This is explained by the strategic challenges these types of activities face in the local, regional and/ or global market. Businesses in the accommodation and food services sector need to have well-developed websites and social media to remain competitive.

The Albanian companies have been increasingly using social media (Facebook, LinkedIn, Twitter, YouTube, etc.). The report shows that social media was used by $46.8 \%$ of enterprises using computers with internet access, from $38.9 \%$ in 2016. The comparison in a continental level reveals a very similar situation. According to DESI 2017 "SMEs are relatively active on social media (44\%) and the usage of mobile internet to allow employees to exploit business application is also becoming more common". The main intentions of such use in $79.6 \%$ of enterprises during 2017 were to improve the image of the enterprise or the product market (e.g. for advertising, marketing of a new product, etc.). Another intention of using social media, from $20 \%$ of enterprises, was to share opinions, ideas or knowledge within the enterprise (INSTAT, 2018).

The main factor that has encouraged the use of social media, much more than other indicators of DT integration, is its low cost, compared to approaches of DT use like electronic information sharing (ERP systems), e-Invoices, e-commerce sales, etc. Another reason revealed during the interviews is the ease of using social media, that comes from its user-friendly configuration (design) and usage experience for individual needs. Consequently, this is an indicator with high growth potential and a positive impact to the competitiveness of the companies, especially those of type B2C.

The dimension of e-commerce has a modest position in the survey done both from the national organization and the study authors. One of three indicators (ref. Fig. 3) is calculated, showing that only $7.7 \%$ of enterprises have sold products / services via their website or dedicated applications in 2017, from $7.1 \%$ in the previous year. Generally, electronic commerce is carried out by enterprises operating in the Information and communication activities by $31.8 \%$, transport and storage activities by $25.2 \%$ and 


\section{Journal of International Cooperation and Development \\ www.richtmann.org/journal \\ Vol 3, No 1, May 2020}

administrative and support service activities by $14.1 \%$. Figures are low for the other economic sectors, as well as compared to $17.8 \%$ of EU survey for 2017 . The main reasons are the same with those announced by EU survey "SMEs (10-249 employees) that do not sell on the web give as their main reason that their products and services are not suitable. This might be reflected by the second most common obstacle: that the cost of investing in web sales is too high compared to the benefits" (DESI 2016).

Despite the late initiation of DT integration assessment in the Albanian environment, the above theoretic review, survey results and analysis permit drawing of several conclusions that follow.

\section{Conclusions}

ICT has emerged over the past decade as a key technology than can transform economic and social activity. It is significantly contributing to economic growth in most countries by bringing higher factor productivity, lower cost of goods and services, newer products and services re-inventing traditional industries, new organizational and/ or business models.

However, achieving benefits from investment in ICT is not straightforward. It typically requires complementary investments and changes in human capital, organizational restructuring and innovation.

The survey of ICT diffusion in the Albanian business environment reveals achievements as well as 'lagging behind' indicators which, in turn, are proper opportunities for advancement in short and medium -term. It brings to the main findings that:

- the digital technologies are spreading with varying speed in Albanian businesses, according to their size and sector of activity;

- the measuring of all recommended indicators is still difficult, due to low levels and missing information;

- it is not yet possible to provide aggregate indexes for the integration of DT in Albanian business;

- the human capital/ qualified workforce is amongst the main drivers to bring forward the introduction of new technologies, increase the use of existing DT in all economic activities and push the education of more employees with IT skills and competencies.

Research work, higher education system and public policies might contribute to the awareness of companies and their capabilities for a better use of information and communication technologies, similarly to countries in a regional and global level. 
www.richtmann.org/journal

Vol 3, No 1, May 2020

\section{References}

Boudreau J., In a new Era of work, skills are lost in translation, March 25, 2015, CFO.com;

Burning Glass Technologies, Crunched by the Numbers: The Digital Skills Gap in the Workforce, Boston, USA, March 2015;

Drejtoria e Pergjithshme e Tatimeve (General Tax Directorate) https://www.tatime.gov.al/

European Commission, Digital Economy and Society Index Report 2018, Integration of Digital

Technologies retrieved on 21.02.2019 from https://ec.europa.eu/digital-single-

market/en/integration-digital-technology

European Commission, International Digital Economy and Society Index Report 2018, Final

Report, ISBN 978-92-79-85699-0

GSM Association, The mobile economy 2018;

INSTAT, http://www.instat.gov.al/ (retrieved on 21.02.2019)

INSTAT, Teknologjia e Informacionit dhe Komunikimit ne ndermarrje (Information and Communication Technology in Enterprises), 2017

ITU, ICT Centric Innovation Ecosystem, Country review Albania, Report June 2016

London School of Economics and Political Science, The Evolving Role of ICT in the Economy, UK, June 2018;

Manyika J., Lund S., Robinson K., Valentino J., and Dobbs R., A labor market that works: connecting talent with opportunity in the digital age, June 2015 McKinsey \& Company

Ministry of Innovation and Public Administration, Albania 2014, Cross-Cutting Strategy "Digital Agenda of Albania 2015-2020".

OECD 2002, Measuring the Information Economy, OECD Publishing, Paris;

OECD 2017, OECD Digital Economy Outlook 2017, OECD Publishing, Paris;

Porter M. E., Heppelmann J.E., Why every organization needs an augmented reality strategy,

Harvard Business Review, November 2017; https://doi.org/10.1787/9789264276284-en.

(retrieved on 21.02.2019)

Telekom Albania, Corporate Responsibility Report 2017, Tirana.

UNESCO, Building tomorrow's digital skills - what conclusions can we draw from international

comparative indicators, Working paper on Education policy, 2018, France;

http://aita-al.org/ (retrieved on 21.02.2019)

https://akep.al/wp-content/uploads/images/stories/AKEP/publikime/raporte/ (retrieved on

21.02.2019)

http://www.itu.int/net4/itu-d/idi/2017/index.html (retrieved on 21.02.2019)

https://www.oecd-ilibrary.org/science-and-technology/information-and-communication-

technology-ict/ (retrieved on 21.02.2019) 